\title{
Médiévales
}

Langues, Textes, Histoire

56 | printemps 2009

Pratiques de l'écrit

\section{Myriam WHITE-LE GOFF, Envoûtante Mélusine, Paris, Klincksieck (Les grandes figures du Moyen Âge), 2008, 234 p.}

\section{Anna Caiozzo}

\section{(2) OpenEdition}

1 Journals

Édition électronique

URL : https://journals.openedition.org/medievales/5617

DOI : 10.4000/medievales. 5617

ISSN : 1777-5892

Éditeur

Presses universitaires de Vincennes

Édition imprimée

Date de publication : 30 juin 2009

Pagination : 186-189

ISBN : 978-2-84292-232-0

ISSN : 0751-2708

\section{Référence électronique}

Anna Caiozzo, « Myriam white-Le goff, Envoûtante Mélusine, Paris, Klincksieck (Les grandes figures du Moyen Âge), 2008, 234 p. », Médiévales [En ligne], 56 | printemps 2009, mis en ligne le 21 septembre 2009, consulté le 24 avril 2022. URL : http://journals.openedition.org/medievales/5617 ; DOI : https:// doi.org/10.4000/medievales.5617

Ce document a été généré automatiquement le 24 avril 2022.

Tous droits réservés 


\title{
Myriam WHITE-LE GOFF, Envoûtante Mélusine, Paris, Klincksieck (Les grandes figures du Moyen Âge), 2008, 234 p.
}

\author{
Anna Caiozzo
}

Depuis l'ouvrage imagé de Françoise Clier-Colombani (La fée Mélusine au Moyen Âge, Images, mythes et Symboles, Paris, Le léopard d'or, 1991) dont elle fut le sujet de thèse tout comme celui de Claude Lecouteux, la fée Mélusine demeure un sujet en constant renouvellement, signe de la polysémie d'un personnage imaginaire d'une richesse inépuisable. L'étude de Myriam White-Le Goff n'est pas sans faire écho à celui de Philippe Walter (La fée Mélusine, le serpent et l'oiseau, Paris, Imago, 2008) qui présentait la figure de Mélusine du point de vue de la mythologie comparée mais aussi de la topographie et de la symbolique des lieux que la fée visita et hanta dans l'espace français. P. Walter apporte sa contribution par le biais des mythes en définissant l'archétype de la femme serpent ou poisson dans diverses civilisations, la polysémie de la légende mélusinienne autour de temps forts à nouveau évoqués dans son sillage par Myriam White-Le Goff : les fonctions de la fée comme divinité de la première fonction, son mariage avec Raymondin, mariage de type hiérogamique entre humain et créature divine, et la triste constatation de l'impossible union entre deux natures ontologiquement différentes; la continuité de l'œuvre mélusinienne à la fois dans le paysage français mais aussi par sa filiation et ses curieux enfants dotés de dons, celui de double vue en particulier; enfin dans la geste mélusinienne, le souvenir d'anciennes pratiques sociales, le matriarcat déclassé par le triomphe des sociétés patriarcales et masculines. Tous ces points sont ici également évoqués dans une perspective différente et d'une grande fraîcheur : l'humanité et la féminité de la fée. Car les cinq chapitres de ce petit ouvrage illustré des planches du fac-simile d'un incunable de 1478 nous emmènent à la rencontre d'une créature émouvante, sensible, aimante, pieuse, d'une indicible beauté, en somme une "femme ", nommée Mélusine. Car la démonstration de Myriam White-Le Goff, si elle se perd souvent par des redites sur l'histoire du couple 
maudit et de sa progéniture, est avant tout centrée sur la ré-humanisation de Mélusine. Trois axes emportent le lecteur vers le monde merveilleux des fées et celui plus compliqué des hommes où elles aspirent à vivre comme des humaines. Qu'est-ce qu'une fée ? C'est ce que le premier chapitre s'emploie à définir avant que les trois suivants ne nous plongent paradoxalement au cœur de son humanité.

2 Mélusine est elle-même issue d'une union « exogamique » entre le roi d'Écosse Hélinas, et la fée Présine, dont la voix l'avait envoûté. De cette union naquirent trois petites filles, Mélusine, Mélior et Palestine que Présine emporta dans sa fuite dans l'île d'Avalon pour punir son époux qui venait de transgresser l'interdit posé par la fée : son épouse en couches. Cet interdit aurait dû être explicité au-delà des développements sur l'androgynie, car il conditionne en fait la véritable nature de la fée et son mode de reproduction comme créature hermaphrodite. Mais, devant le chagrin de leur mère, chagrin sur la nature duquel elles se trompent, soucieuses de la venger de l'offense qui lui est faite, les petites fées emprisonnent dans les entrailles d'une montagne magique leur père qui finira ses jours avant d'être enseveli, tel un pharaon, dans un magnifique tombeau. La sépulture d'Hélinas, sur laquelle l'auteur insiste beaucoup, possède néanmoins son équivalent en Orient dans le Shâh Nâmeh, le Livre des rois de Firdawsî (début $\mathrm{du} \mathrm{XI} \mathrm{I}^{\mathrm{e}}$ siècle) où les rois exceptionnels sont ensevelis assis sur leur trône sur le mont Alburz, la montagne sacrée, dans un tombeau fastueux, lieu de passage entre deux mondes, tout comme Hélinas au milieu de magnifiques joyaux. Les jeunes filles, punies de leur outrecuidance sont ensorcelées par leur mère, toujours amoureuse de leur père, tout comme Mélusine aimera Raymondin à jamais malgré l'outrage qui lui sera fait. Car l'histoire de Présine et d'Hélinas est en soi une hiérogamie, et leurs filles sont certes des créatures exceptionnelles mais à demi-humaines et Présine semble bien être l'hermaphrodite que Philippe Walter subodorait. Ces trois filles sont d'ailleurs associées aux divinités védiques des trois fonctions: Mélior symbolise la guerre dans son château arménien de l'épervier attendant le prince qui veillera trois jours et trois nuits; Palestine, divinité de la troisième fonction, est enfermée dans le château du mont Canigou infesté de serpents, royaume de grottes cavernes, chtonien et infernal, gardé par un monstre ; enfin Mélusine, qui chaque samedi se métamorphose en hybride mi-femme mi-serpent, incarne la souveraineté.

3 L'histoire de Mélusine et Raymondin se situe donc dans le sillage de celle de ses propres parents : une union placée sous le signe de l'amour, de la fécondité, de la gloire et de la richesse mais irrémédiablement compromise par un dénominateur commun: la trahison ou perte de la confiance mutuelle inspirée par un tiers jaloux de cet incroyable bonheur. Au-delà, la rencontre est placée sous de mauvais auspices, le crime, celui contre son père qui condamne la fée à errer, celui - accidentel - contre le comte Aymeri, homme «clairvoyant ", qui accepte cependant son destin pour la réalisation d'un grand dessein: l'aventure mélusinienne. Ce double préjudice conditionne la tragédie finale.

M. White-Le Goff nous présente les grands traits du personnage féerique: un être surnaturel qui se déplace entre le monde des hommes, très lié au monde celtique (Bretagne et Écosse, îles), et un monde parallèle et merveilleux, montagnes, grottes, espaces chtoniens peuplés de créatures parfois effrayantes - (serpents, dragons, géants) parfois analogues aux hommes (chevaliers, artisans, courtisans)-, créatures qui peuvent à sa demande la suivre et la servir. La fée est pourvue d'une panoplie d'objets merveilleux qu'elle offre aux proches qu'elle veut protéger. Mais elle est aussi dotée de 
pouvoirs surnaturels et voit dans le passé comme dans l'avenir. La fée peut en outre offrir l'impression que le monde d'où elle vient est le reflet de celui des hommes (costumes, langages, valeurs aristocratiques, divertissements, etc.). Mélusine, dans sa dimension vénusienne, est aussi associée à la beauté, à l'harmonie : " la beauté est si intimement liée à la nature de la fée que son histoire ne peut se penser sans cette dimension esthétique » (p. 109). En outre, elle possède la capacité de se métamorphoser chaque samedi en être mi-femme mi-serpent, et pour finir elle se dote d'ailes et s'envole. Si les occidentaux comme les orientaux ont beaucoup hésité entre sirènes ailées de type harpies, ou à queue, Mélusine, lors de sa fuite, revêt bien en fait les caractéristiques d'une divinité infernale de type Lilith, à la fois serpent et oiseau. Et l'on retrouve ici la marque négative de l'hybridation assimilée à la monstruosité qui, en Occident comme en Orient, est interprétée comme marque de la punition divine. En revanche, pourquoi vouloir identifier Mélusine au sanglier? Certes les fées peuvent se métamorphoser, mais le sanglier est l'animal symbole de la chasse de l'Atlantique à l'Asie centrale, il est même l'avatar d'un dieu d'origine védique, Vahagn ou Verethragna, et de ce fait s'il ne s'apparente pas à Mélusine, il peut être identifié à l'une des sœurs, Mélior, ce qui renvoie à l'hypothèse bien démontrée par Philippe Walter : Mélusine et ses sœurs ne formant qu'une seule et même entité.

5 La véritable question est posée page 48 : les fées vivent-elles dans leur monde comme des humains ou alors donnent-elles le change en se comportant comme les hommes? Car, au fond, nul ne sait comment les fées vivent entre elles loin des regards humains. La thèse centrale repose sur l'incroyable humanité ou humanisation de Mélusine qui tend de toutes ses fibres à devenir une épouse parfaite, une mère aimante, une aristocrate bâtisseuse, une chrétienne exemplaire. Tous ces traits magnifiés par M. White-Le Goff nous la présentent comme une candidate à l'incarnation, décidée à renoncer à sa condition d'immortelle pour l'amour d'un homme exceptionnel.

6 Via cette démarche pathétique car vouée à l'échec par le précédent familial, on observe que le roman mélusinien défend un certain nombre de valeurs qui, à l'époque de Jean d'Arras et de Coudrette, sont fondatrices de la société nobiliaire et de son imaginaire, telle qu'elle a été mise en valeur ces trente dernières années par les travaux de Georges Duby, Jean Flori, Michel Pastoureau ou Eric Koehler : ainsi, le mariage d'amour qui va déclasser les mariages arrangés, la bénédiction de l'union par l'Église; la constitution d'un lignage fondé sur la mémoire familiale (le tombeau d'Hélinas) et les liens du sang ; l'adoption d'un ancêtre éponyme commun, telle Mélusine pour les Lusignan. Mais aussi l'identification aux valeurs de la chevalerie dont les fils de Mélusine sont les fiers représentants. Et, de fait, le chapitre sur les fils de Mélusine qui tente de rattacher la légende à la réalité pour quelques personnages particuliers, présente des éléments certains d'intérêt pour l'historien médiéviste.

7 Mélusine illustre, par sa geste personnelle, les qualités requises par une femme noble, et se révèle au-delà des apparences une créature de Dieu, par son amour pénétré d'une étonnante humanité dans son rôle d'épouse, de noble et surtout de mère. Elle est par essence la femme médiatrice, celle qui permet à Raymondin de passer à l'âge adulte et participe à son accomplissement comme chevalier, comme chrétien et comme père. Aristocrate de son temps, elle procède à l'aménagement de son territoire, au défrichement et à la mise en culture, bâtissant ponts, forteresses (dont Lusignan) et églises. Mélusine réussit en quelque sorte son incarnation puisqu'elle est indissociablement liée à un lieu, le Poitou. Quelques belles pages très émouvantes nous 
permettent en outre d'approcher la fée dans sa dimension maternelle: féconde, aimante, attentionnée, elle allaite ses deux derniers après avoir été chassée, et veille toujours sur ses enfants (exception faite d'Horrible qu'elle voue à la mort), sorte de déesse mère gardienne de l'ordre du cosmos plus qu'entité maléfique comme le suggère l'auteure. Elle incarne bien la société matriarcale primitive et sa chute symbolisant le passage au régime patriarcal.

Dans ce contexte, la légende de Mélusine est aussi, comme l'a compris M. White-Le Goff, en dehors des incompatibilités propres aux mariages entre hommes et dieux, révélatrice des tabous de l'époque médiévale: l'exogamie d'une part et la difficulté pour hommes et femmes de s'apprécier en toute égalité comme le couple en donne l'exemple. Ce dernier trait renvoie le lecteur à une interrogation plus profonde de type anthropologique: outre la nécessité de promouvoir l'ancêtre totémique comme créature hors du commun, le sort de Mélusine renvoie semble-t-il à une double interprétation. D'une part, il stigmatise sans ambigüité la fin d'un monde et le passage au patriarcat. D'autre part, il souligne une réalité patente : l'impossible reconnaissance de la femme dans la société des hommes. Le destin mélusinien présente, en effet, une allégorie de la femme, incomprise, maltraitée pour la part de mystère qu'elle possède et son pouvoir incommensurable, de mettre au monde l'homme, comme Mélusine Raymondin, et par dessus tout, pour sa capacité à donner la vie. A travers la figure sublimée de la fée, Mélusine demeure une médiatrice entre deux mondes. 